\title{
LA I REPÚBLICA PORTUGUESA Y LA II REPÚBLICA ESPAÑOLA EN PERSPECTIVA DE GÉNERO. ESTUDIO COMPARADO
}

\section{María de la Paz Pando Ballesteros}

\section{Resumen}

Las conexiones entre los procesos políticos experimentados en Portugal y en España, a lo largo de su historia contemporánea, nos han llevado a preguntarnos si tales similitudes se producirían también entre la I República portuguesa y la II República española, en concreto en el tratamiento que dichos regímenes confirieron a las mujeres. Para aclarar esta cuestión hemos utilizado las políticas de género como instrumento de análisis de la naturaleza y las características de las Repúblicas de la Península Ibérica, como se ha realizado para otros periodos, y la historia comparada, para valorar sus respectivas respuestas a las reivindicaciones de los derechos de las mujeres y de la igualdad, llegando a interesantes conclusiones.

Palabras clave: I República portuguesa, II República española, historia de las mujeres, feminismo ibérico, derechos de las mujeres.

\section{Resumo}

A I República Portuguesa e a II República Espanhola numa perspetiva de género. Estudo comparativo

As ligações entre os processos políticos vividos em Portugal e na Espanha ao longo da sua história contemporânea levaram-nos a questionar se tais semelhanças ocorreriam também entre a Primeira República Portuguesa e a Segunda República Espanhola, especialmente no tratamento que estes regimes deram às mulheres. Para esclarecer esta questão, utilizamos as políticas de género como instrumento de análise da natureza e características das Repúblicas da Península Ibérica, como tem sido feito para outros períodos, e a história comparada, para avaliar as suas respetivas respostas às reivindicações dos direitos das mulheres e da igualdade, chegando a conclusões interessantes.

Palavras-chave: I República Portuguesa, II República Espanhola, história das mulheres, feminismo ibérico, direitos das mulheres.

Universidad de Salamanca - C/ Cervantes s/n, 37001,Salamanca, España.

Dirección postal: Departamento de Historia Medieval, Moderna y Contemporánea, Facultad de Geografía e Historia. C/ Cervantes s/n, 37001, Salamanca, España.

Correo electrónico: mpaz@usal.es 


\begin{abstract}
The I Portuguese Republic and the II Spanish Republic in a Gender Perspective. A comparative study

The connections between the political processes experienced in Portugal and Spain throughout their contemporary history have led us to wonder whether such similarities would also occur between the First Portuguese Republic and the Second Spanish Republic, specifically in the treatment that said regimens accorded to women. To clarify this question, we have used gender policies as an instrument for analyzing the nature and characteristics of the Republics of the Iberian Peninsula, as has been done for other periods, and comparative history to assess their respective responses to the claims of women's rights and equality, reaching interesting conclusions.
\end{abstract}

Keywords: I Portuguese Republic, II Spanish Republic, women's history, Iberian feminism, women's rights.

\title{
Breve estado de la cuestión y contexto
}

Gran interés ha despertado entre los/as historiadores/as de ambos lados de la frontera peninsular el estudio tanto de la I República portuguesa como de la II República española, ambos periodos cruciales en la historia contemporánea de sus respectivos países.

Disponemos de numerosas publicaciones sobre el citado periodo portugués de las que han dado cuenta algunos estudios historiográficos, caso de los artículos publicados por José Tengarrinha e Hipólito de la Torre, en 1997, en los que repasaban la bibliografía portuguesa y española al efecto, así como la actualización de la misma realizada por Francisco de Luis en 2005 (De la Torre 1997, 65-80; Tengarrinha 1997, 19-64; De Luis 2005, 221-248).

Sobre la historia general de dicha época recordamos la obra coordinada en 2010 por Fernando Rosas y Maria Fernanda Rollo y, de esta última, el diccionario sobre la historia de la I República y el republicanismo portugués (Rosas e Rollo 2010; Rollo 2013-2014). En cuanto a determinados aspectos concretos del periodo al que nos referimos, destacamos la tesis doctoral de Alfredo Comesaña relativa a la influencia de los acontecimientos internacionales de 1919 en Portugal (Comesaña 2014). Por su parte, utilizan la perspectiva comparada Juan Carlos Jiménez al estudiar los países ibéricos ante el fin de siglo XIX (Jiménez 2000, 25-40), y Jon Penche al analizar el republicanismo (Penche 2011, 155-170).

La II República española también ha sido uno de los periodos más estudiados en España, tanto de forma general como sobre cuestiones específicas. Citamos el artículo de José Luis Ledesma, de carácter historiográfico, y la monografía de Ángel Luis López Villaverde, publicados ambos en 2017 (Ledesma 2017; López 2017). En relación a la historiografía portuguesa sobre este tema, menos numerosa que la existente sobre la Guerra Civil y la Dictadura, es de destacar la obra del historiador César Oliveira, Portugal e a II República de Espanha (1931-1936) (Oliveira 1985). 
Menos abundantes son las investigaciones realizadas sobre la situación de las mujeres durante esos mismos periodos. Para el caso portugués es obligada la referencia a obras como las publicadas en 2007 por Maria Alice Samara y en 2008 por João Esteves (Samara 2007; Esteves 2008). En 2011 aparecía una monografía de Fátima Mariano y una obra colectiva coordinada por los profesores Zília Osório de Castro, João Esteves y Natividade Monteiro (Mariano 2011; Castro, Esteves e Monteiro 2011), y en fechas más recientes cabe citar la obra de Irene Flunser Pimentel y Helena Pereira de Melo (Pimentel e Melo 2015), además de las obras dedicadas a determinadas mujeres relevantes del momento. Son de destacar del mismo modo los trabajos de la española Rosa $\mathrm{M}^{\mathrm{a}}$. Ballesteros sobre los orígenes del movimiento feminista portugués (Ballesteros 2002).

Entre la numerosa bibliografía relativa a las españolas durante la II República, destacamos los capítulos referidos al periodo en la obra dirigida por Josefina Cuesta (Cuesta 2003), y en la monografía de Guadalupe Gómez-Ferrer Morant (Gómez-Ferrer 2011), así como los que Dolores Ramos dedica al tema, en 2013 y 2014, en diversas obras de carácter colectivo (Ramos 2013, 317-333; Ramos 2014, 21-46). Al año siguiente la Revista de Historiografía publicaba otro enriquecedor estado de la cuestión sobre el feminismo español del primer tercio del siglo XX (Branciforte 2015, 235-254).

Las similitudes entre los procesos políticos de ambos países ibéricos a lo largo de su historia han favorecido el interés por una Historia Comparada, útil método de trabajo que permite desentrañar tanto los paralelismos como las diferencias entre ellos. Por nuestra parte, dicho interés ha quedado de manifiesto a través de varias iniciativas. Ha sido muy interesante comparar franquismo y salazarismo desde una perspectiva de género. Como es sabido, no son pocos los investigadores que han propuesto utilizar las políticas de género como herramienta metodológica desde la que analizar la naturaleza o la tipología de las dictaduras occidentales del periodo de entreguerras. Nos preguntábamos, en esta ocasión, si tales similitudes se producirían también entre otros periodos, quizá no coincidentes cronológicamente de forma estricta, pero que habrían compartido regímenes políticos afines tal sería el caso de la I República portuguesa y de la II República española utilizando, también en ese caso, la perspectiva de género como elemento comparativo.

Aún a riesgo de caer en generalizaciones simplificadoras, por la dificultad para la realización de un análisis profundo debido a la limitación de espacio, encontramos numerosas analogías entre las Repúblicas ibéricas, pese a no transcurrir en contextos internacionales idénticos. El proceso de llegada de ambos regímenes fue semejante, confirmándose en los dos países la presencia de dictaduras con las que los respectivos monarcas llegaron a sentirse muy identificados. Por otro lado, los problemas económicos, motivados por la expansión colonial en el caso luso y por las guerras con Marruecos en el español, así como el crecimiento de las tensiones sociales que desembocaron en el regicidio de D. Carlos y el exilio de su sucesor, Manuel II, tras el éxito de la revolución republicana del 4 de octubre de 1910, o el triunfo de 
los partidos republicano-socialistas en las elecciones municipales españolas del 12 de abril de 1931, que provocaron el exilio de Alfonso XIII y la proclamación de la II República, evidencian puntos en común. No solo los comienzos contaron con semejanzas, también compartieron la inestabilidad en su desarrollo, así como su final, marcado por Golpes de Estado que, aunque con características y consecuencias diferentes, terminaron dando paso a las más largas dictaduras conservadoras europeas del periodo de entreguerras. Durante este tiempo, también las mujeres de ambos países experimentaron procesos muy similares como trataremos de reflejar.

\section{Demandas y conquistas de las mujeres en la I República Portuguesa}

Fue durante el gobierno provisional de la I República portuguesa cuando las mujeres vieron reconocidos parte de los derechos que venían reivindicando desde tiempo atrás.

La movilización de las portuguesas arrancó a finales del siglo XIX, caracterizándose por el tono moderado de sus actuaciones al igual que el de sus coetáneas españolas.

En 1899 la escritora Alice Pestana, residente en España desde 1901, fundó la Liga Portuguesa da Paz, y dentro de ella, en 1906, la Secção Feminista da Liga Portuguesa da Paz desde la que se reivindicó expresamente la igualdad. No obstante, tanto desde ella, como desde otros grupos emergentes, se abogaba por una emancipación femenina a través de la educación y la cultura, y en menor medida por la ciudadanía política, pensamiento compartido, en un primer momento, por no pocos grupos de europeas y españolas. Al igual que ellos, las portuguesas también bebieron de las corrientes ideológicas inspiradas en el librepensamiento, el positivismo, la masonería y el laicismo, este último con mayor peso conforme iba pasando el tiempo (Ballesteros 2002, 169, 173).

La formación de una organización estrictamente feminista se convirtió en una prioridad desde principios del siglo. En 1908 se formó la Liga Republicana das Mulheres Portuguesas (LRMP), y con la llegada de la República floreció un asociacionismo feminista representado, entre otros grupos, por la Associação de Propaganda Feminista (APF), fundada por Carolina Beatriz Ângelo. Desde ellos las reivindicaciones sociales, civiles y educativas de primera hora fueron dejando paso a la lucha por los derechos políticos, así como al impulso de su internacionalización (Esteves 2011b, 38).

Si bien los primeros contactos internacionales de las lusas se realizaron a través del feminismo pacifista, la entrada de la APF en la International Woman Suffrage Alliance (IWSA), en 1911, determinó dicha internacionalización, mientras el Conselho Nacional das Mulheres Portuguesas (CNMP), creado en 1914 por Adelaide Cabete, se convirtió en una ramificación del International Council of Women (ICW) (Esteves 2011a, 163-175; Cova 2011, 27-40). 
Resulta pertinente mencionar la Liga Internacional de Mujeres Ibéricas e Iberoamericanas, fundada en 1922, que vino a integrar en una misma organización a la Cruzada das Mulheres Portuguesas, creada en 1916 por Ana de Castro Osório, y a la Cruzada de Mujeres Españolas, fundada en 1920 por Carmen de Burgos, a imagen del grupo portugués, con el objetivo de potenciar la influencia de las organizaciones feministas iberoamericanas. La estrecha amistad entre ambas escritoras y sus muchos puntos en común propiciaron un fluido intercambio cultural entre España y Portugal (Núñez 2014).

Previamente a la proclamación de la República sus valedores invitaron a las feministas a que coadyuvaran a su advenimiento. Las portuguesas conquistaron así el espacio público y la esfera política, hasta entonces exclusivamente masculinos, aunque la Constitución de 1911 les negara el derecho al voto. Se cumplía así, también en esta ocasión, la tesis de Celia Amorós, que explica estos comportamientos, frecuentes a lo largo de la Historia, argumentando que en los momentos en los que se producen conflictos o transiciones políticas, cuando distintos grupos ideológicos masculinos compiten por alcanzar el poder, en esos instantes de pugna, las mujeres tienen cierta capacidad para plantear sus reivindicaciones y son llamadas a presentar sus propios modelos de feminidad. Sin embargo, existe el riesgo, proclama la filósofa española, de que, cuando uno de esos grupos en liza se consolide en el poder, plantée su propia política de género, evitando la participación femenina y asignándole a la mujer una identidad y unos roles diferentes a los reivindicados por ellas (Amorós 2009).

Como anticipábamos, durante el gobierno provisional las portuguesas alcanzaron sus más importantes logros. De forma paralela a las medidas de laicización de la sociedad, se produjeron una serie de mejoras en la situación civil y social de las mujeres que habían sido intensamente reivindicadas por las feministas desde principios de siglo.

En este sentido, en noviembre de 1910 era aprobada la Ley del Divorcio, cuyo debate social y político había abierto un artículo de Ana de Castro Osório publicado en 1908 en el Jornal da Mulher (Castro 2011, 85). La Ley establecía que el divorcio podía ser solicitado por uno de los cónyuges o de forma conjunta, pudiendo contraer posteriores nupcias. No obstante, a las mujeres se les permitía volver a casarse después de un año de haber obtenido el divorcio mientras que los hombres podían hacerlo después de seis meses (Lei do Divórcio 1910).

$\mathrm{Al}$ mes siguiente se aprobaron las Leyes de la Familia que establecían el matrimonio civil, imponían la investigación de la paternidad y la responsabilidad económica del padre sobre los hijos habidos fuera del matrimonio. Además, se derogaron los artículos que estipulaban que la mujer debía obediencia al marido, y la sociedad conyugal pasó a basarse en la libertad y la igualdad (Leis da Familia 1910, 13).

Más difícil fue la conquista de los derechos políticos. Tanto para Ana de Castro Osório, como para Carolina Ângelo, el acceso a la ciudadanía política se 
convirtió en una prioridad. Aunque su defensa no estuvo exenta de polémica, produciéndose un intenso debate sobre qué mujeres deberían acceder a tal derecho. Esta situación provocó discrepancias entre las feministas y la ruptura de la LRMP, de la que salieron Ana de Castro Osório y algunas seguidoras para fundar, en 1911, la Associação de Propaganda Feminista desde la que defendieron el voto solo para las mujeres emancipadas que contaran con un nivel educativo que les ofreciera independencia frente a la Iglesia, o que pagaran impuestos, mientras que Maria Velada, pese a declararse antisufragista, rechazaba tales argumentos por desiguales y aristocráticos.

Finalmente, la primera ley electoral cuyo texto reconocía el derecho al voto a los “ciudadanos portugueses con más de 21 años, que supieran leer y escribir y fueran jefes de familia" ${ }^{1}$, eliminando el requisito del censo, impidió el ejercicio de dicho derecho a las mujeres, frustrando las expectativas de las sufragistas.

Lejos de acatar la norma, Carolina Ângelo se resistió a su cumplimiento y, apoyándose en su condición de cabeza de familia, al ser una viuda con una hija menor a su cargo, y en el sentido genérico de la redacción del texto, que no excluía expresamente a las mujeres, reclamó su derecho a votar hasta que el Tribunal de justicia terminó dándole la razón, convirtiéndose en la primera mujer de toda la Europa mediterránea en ejercer el derecho al voto en las elecciones constituyentes el 28 de mayo de 1911 (Tavares 2013).

En poco tiempo se subsanaría el lapsus de redacción de modo que la reforma electoral de 1913 ya especificaba entre los requisitos de los electores el de ser ciudadanos portugueses de sexo masculino, premisa que fue ratificada nuevamente en 1918. Los republicanos incumplían así su compromiso con el reconocimiento del derecho al voto femenino, que no implementarían por miedo a que los votos de las mujeres revirtieran contra la República, o como explica Ramos Palomo para el caso español, por el miedo de determinados grupos gubernamentales a perder su poder (Ramos 1988, 563-573).

Sirvieron de poco las protestas de las feministas que vieron traicionadas sus expectativas y se lamentaban de que pudieran ejercer tal derecho los analfabetos mientras se les negaba a las profesionales portuguesas con solvencia económica (Ballesteros 2002, 210). Argumentos y lamentos compartidos por sus coetáneas españolas, italianas y francesas.

Con el paso del tiempo, las sucesivas reformas electorales de 1931, 1956 y 1968, fueron permitiendo el acceso a las urnas a algunas mujeres con estudios, o cabezas de familia, con propiedades y con la posibilidad de pagar cierto nivel de rentas, siempre con una notable discriminación respecto a los hombres en cuanto a los requisitos exigidos, y no sería hasta la llegada de la democracia cuando las portuguesas tuvieran pleno reconocimiento de la ciudadanía.

La traducción de esta y el resto de las citas literales son responsabilidad de la autora de este artículo. 
Para Gisela Bock, el reconocimiento del voto femenino estaría estrechamente relacionado con intereses partidistas, considerando la historiadora alemana que, especialmente en Europa, se habría producido una interacción entre la eliminación de las barreras de clase y las de sexo conforme a la cual la concesión del voto femenino sucedería a la del sufragio universal masculino, premisa que también parece cumplirse en el caso portugués y español (Bock 2001, 172-173).

Se ha dicho con frecuencia que la constitución republicana de 1911 consagró derechos fundamentales como la igualdad. En efecto, en el título II, el de los "Derechos y Garantías individuales", en el artículo $3^{\circ}$, §2 ${ }^{\circ}$ reconocía que "la ley es igual para todos ...". Sin embargo, resulta llamativo que ningún artículo especificara la no discriminación por razón de sexo. Tampoco concretaba, en las disposiciones generales, quienes eran ciudadanos portugueses a efecto de derechos políticos, dejando la puerta abierta a la imprecisión (Constitución portuguesa 1911).

A pesar de los reveses legislativos mencionados, la I República favoreció el acceso de las mujeres a profesiones hasta entonces no permitidas, así como al funcionariado público. La propia Ana de Castro Osório fue nombrada Subinspectora de Trabajos Técnicos Femeninos en 1916. Ya en la segunda década del siglo XX las portuguesas accedieron a la docencia universitaria, fueron abogadas y notarias, se revalorizó la instrucción femenina y triunfó la coeducación hasta la dictadura militar de mayo de 1926. Aunque no todos los sectores aceptaron de buen grado esta mayor presencia femenina en el espacio público y en ámbitos de influencia, los conservadores por convicción propia y los republicanos por las suspicacias ante una potencial difusión de ideas contrarias a las republicanas que las mujeres pudieran propiciar.

\section{La II República española y las mujeres}

En España la movilización de las mujeres se produjo con un considerable retraso no solo respecto a la de las británicas y norteamericanas, sino también a la de las portuguesas. Para muchas autoras las causas radicarían en el escaso desarrollo que tuvieron las clases medias, germen del origen de la conciencia feminista en otras latitudes, así como por la presencia de unas clases populares que precisaban organizarse para satisfacer necesidades más perentorias (Scanlon 1986).

Resulta llamativo que el discurso sobre la conveniencia de la participación de las mujeres en los asuntos públicos precediera a su movilización. Como en Portugal, las fuerzas conservadoras fueron las que primero intentaran captar, a comienzos del siglo XX, a las mujeres en beneficio de su causa sin pretender emanciparlas, ni cambiar las relaciones de género patriarcales vigentes.

Hasta bien entrado el siglo no aparecieron grupos organizados de mujeres para defender sus derechos como colectivo. Con anterioridad a estas fechas, contamos con figuras aisladas que reivindicaban la emancipación femenina desde diferentes ámbitos, con la preocupación de determinados reformistas que impul- 
saron la educación de las mujeres como prerrequisito para mejorar su situación, así como con algunas revistas escritas por mujeres y dirigidas a ellas. A partir de 1870 también puede apreciarse la creación de algunas secciones de mujeres dentro del movimiento obrero organizado que fueron radicalizándose, formando, en la década siguiente, grupos anarquistas como "Las Mártires del Trabajo" y "Las Desheredadas", entre otras, que incentivaban la afiliación anarcosindicalista y la participación femenina en los conflictos, así como la "Sociedad Autónoma de Mujeres", fundada en Cataluña en 1896 por Teresa Claramunt (Espigado 2002, 51).

Con el cambio de siglo empezaron a abrirse nuevos espacios sociopolíticos de participación ciudadana femenina, emergiendo un importante asociacionismo vinculado al ideario socialista, anarquista y comunista paralelo a la consolidación de grupos de mujeres vinculadas al feminismo laico que habían empezado a aflorar en los años de la intercenturia (Del Moral 2010, 107-138; Aguado e Sanfeliu 2021, 237-263).

No obstante, no fue hasta 1918 cuando aparecieron las dos asociaciones feministas más destacadas. La Asociación Nacional de Mujeres Españolas (ANME), autodefinida como interclasista y apartidista, dentro de su moderación evitó toda colaboración con cualquier otro órgano político o religioso y reivindicó derechos civiles y políticos para las mujeres. Por su parte, la Unión de Mujeres de España (UME) se fundó como una opción interclasista y aconfesional, aunque con un carácter izquierdista, situándose sus socias próximas al Partido Socialista.

A las puertas de la segunda década del siglo, se multiplicaban las asociaciones de mujeres. En 1919 se creaba el Consejo Supremo Feminista de España que reunía a numerosos grupos de mujeres profesionales, mientras la ANME promovía la creación entre las estudiantes universitarias de Juventud Universitaria Feminista (JUF), que pretendía atraerse a las jóvenes que accedían a las facultades. Esta organización tuvo una importante conexión con el exterior a través de la International Federation of University Women (IFUW). Contactos que favorecieron la internacionalización del feminismo español, que llegaba también de forma más tardía que el portugués, pues no sería hasta 1920 cuando Isabel Oyarzábal participara en el Congreso de IWSA.

Además de los grupos que no manifestaban una ideología política definida, las mujeres también fueron afiliándose a partidos políticos de distinto signo, invitadas por sus líderes. Desde finales del siglo XIX, lo hizo la corriente republicana y posteriormente siguieron su ejemplo socialistas, anarquistas, nacionalistas y católicos, que pretendía contrarrestar el empuje que iban adquiriendo las asociaciones de carácter no confesional (Folguera 1994, 488).

Esta importante minoría de feministas españolas trabajó para que la oportunidad que representaba la llegada de la República beneficiase su causa, poniendo todas sus esperanzas en dicho modelo político, al que defendieron con un convencido compromiso, como muy bien señala Rosario Ruiz (Ruiz Franco 2006, 171185), pero, ¿fueron correspondidos dichos esfuerzos y expectativas? 
Como es sabido, el Gobierno Provisional de la II República permitió, mediante el decreto de 8 de mayo de 1931, que las mujeres pudieran ser elegidas diputadas, aunque ignoró la legislación de 1924, que permitía el voto a algunas mujeres en las elecciones municipales, resistiéndose a dejarlas votar. Pese a ello, en las elecciones a Cortes de junio de 1931 resultaron elegidas tres mujeres de un total de 465 diputados, adquiriendo las abogadas Clara Campoamor, del Partido Radical, y Victoria Kent, del Partido Radical Socialista, un relevante protagonismo en las sesiones parlamentarias.

Clara Campoamor fue la única mujer que formó parte de la Comisión Constitucional de 1931, realizando un ingente trabajo para que el texto recogiera los derechos de las mujeres.

Al igual que la Constitución portuguesa, la española reconocía la igualdad de todos/as los/as españoles/as ante la Ley y además explicitaba, en el artículo 25, que el sexo no podría ser causa de privilegio.

Relevante resulta el artículo 43, que mejoraba la posición de la mujer en la familia, tal y como lo había hecho la legislación portuguesa en 1910. Reconoció la igualdad de derechos para ambos cónyuges en el matrimonio, al tiempo que contemplaba su disolución en caso de desacuerdo, aunque la Ley del divorcio no se promulgaría hasta el 2 de marzo de 1932.

En el mismo artículo se recogían las obligaciones de los padres con los/as descendientes, también con los habidos fuera del matrimonio, y se regulaba la investigación de la paternidad, desapareciendo la procedencia sobre la legitimidad o ilegitimidad de los/as nacidos/as. Se protegía así no solamente el estatus de los/ /as hijos/as, también el de las madres, así como su reputación.

El derecho a la asistencia aparecía asimismo en el artículo citado para proteger la maternidad y la infancia, y trasladar al Estado la responsabilidad del cuidado de los/as dependientes de la familia, liberando a las mujeres de tales tareas tradicionalmente feminizadas (Constitución española 1931).

El reconocimiento del derecho al trabajo también incluía a las mujeres. El artículo 33 recogía la libertad de toda persona a elegir profesión, y el 40 prohibía la discriminación por razón de sexo a la hora de ejercer empleos y cargos públicos, aunque en ambos se señalaba que su aplicación estaría supeditada a las limitaciones que impusieran las leyes, dejando así la puerta abierta a excepcionalidades en el acceso o el ejercicio de determinados trabajos por motivos de insalubridad, peligrosidad, dureza, nocturnidad, o estableciendo una edad de incorporación diferente para hombres que para mujeres. En suma, se mantuvo una política proteccionista, en ocasiones, siguiendo las directrices internacionales y siempre cuestionada por las feministas.

Como en el caso portugués, el reconocimiento de derechos civiles y sociales a las españolas generó menos polémica que el de los políticos. El debate sobre del voto femenino en las Cortes de 1931 fue el más encendido de los que se produjeron. 
La cuestión del voto femenino llegó al Parlamento español por primera vez en 1877, pero se desestimó por falta de interés social y no se volvió a plantear hasta 1907, cuando se inició un debate que sucesivamente fue retomado en 1908 y en 1919, aprovechando el apoyo, en este último año, del papa Benedicto XV, que coadyuvó a que los grupos conservadores y católicos abandonaran sus reservas al respecto (Fagoaga 1985).

Como anticipábamos, el Estatuto Municipal de 1924, promulgado por el dictador Primo de Rivera, otorgó, por primera vez, el voto a las mujeres emancipadas y mayores de 23 años en las elecciones municipales, aunque estas no llegaron a convocarse. Como afirmaría Clara Campoamor, fue lo mismo que conceder la "igualdad en la nada" (Campoamor 1981 [1ª ed. 1935], 21).

En las Cortes de 1931 muchos fueron los argumentos de los diputados contrarios al voto femenino, como evidencian las sesiones de las Cortes de los días 1, 2 y 30 de septiembre, que iban desde la perturbación de la tranquilidad de los hogares a razones biológicas, o consideraciones sobre un supuesto comportamiento femenino condicionado por el histerismo o la irracionalidad (Diario de Sesiones de las Cortes 1931, 30, 693-703; Diario de Sesiones de las Cortes 1931, 31, 728-729; Diario de Sesiones de las Cortes 1931, 47, 1337-1342). No obstante, el interés del debate se centró en las posturas encontradas de las dos diputadas allí presentes, Clara Campoamor y Victoria Kent, reflejadas en las intervenciones del día 1 de octubre, pese a que ambas pertenecían a partidos que abogaban por la concesión del voto más adelante, cuando la mujer tuviera una formación política sólida.

Victoria Kent mantuvo la disciplina de partido y, tras dudar entre restringir el voto femenino a universitarias y obreras o posponerlo en el tiempo, optó por la segunda opción al parecerle menos injusta. Nuevamente hacía acto de presencia el miedo a que la influencia de la Iglesia, la poca formación política de las mujeres o su escasa independencia de criterio pudieran condicionar un resultado electoral que comprometiera el futuro de la República.

Clara Campoamor, sin embargo, se opuso a la tendencia segregacionista de su partido y entre las mofas, risas y burlas de los diputados, argumentó que no podía negarse el voto a las mujeres por el principio jurídico de igualdad recogido en la propia Constitución. Rebatió, con datos estadísticos sobre el analfabetismo en España, a quienes acusaban a las mujeres de ignorantes, y frente a quienes apuntaban a la histórica incapacidad de la naturaleza femenina apeló a Unamuno para recordarles que todos/as somos producto de dos seres y recibimos por igual las dos partes de nuestro ser por lo que no habría incapacidad posible, y que los que negaban esta evidencia solo podían hacerlo en virtud de un derecho que habían detentado porque fueron los hombres los que elaboraban las leyes no por un derecho natural que relegara a las mujeres (Diario de Sesiones de las Cortes 1931, 48. 1349-1361).

Finalmente, las votaciones de la Cámara arrojaron un resultado favorable al sufragio femenino, aunque sus detractores trataron de impedirlo presentando dis- 
posiciones adicionales transitorias antes de la votación general de la Constitución (Diario de Sesiones de las Cortes 1931, 83, 2736-2752).

Las dos diputadas protagonistas de la polémica pagaron muy caro sus respectivas posturas parlamentarias (Campoamor 1981 [1 $1^{a}$ Edición 1935]). No obstante, el reconocimiento igualitario del sufragio, así como del derecho de asociación, en los artículos 36 y 39 de la Constitución, impulsaron tanto el asociacionismo femenino de toda ideología, como la presencia femenina en la política. Se incrementó el número de diputadas en las Cortes y, en 1937, fue nombrada ministra Federica Montseny, primera mujer en desempeñar tal cargo en toda Europa occidental.

Pese a las dificultades, durante esta época las españolas gozaron de una serie de derechos fundamentales sin parangón hasta entonces. Entre 1931 y 1936 se legisló a partir del esquema de la Constitución, aunque los avances legislativos, en muchos ámbitos, hubieron de enfrentarse a importantes dificultades en su aplicación.

\section{Conclusiones}

Como ha podido verse, son muchas las similitudes que compartieron las mujeres ibéricas durante los gobiernos republicanos comparados.

Los movimientos de mujeres portuguesas y españolas aparecieron con cierto retraso respecto a los de las anglosajonas y con una gran diferencia en cuanto a sus estrategias de actuación, caracterizándose el feminismo peninsular por el tono moderado de sus acciones, una pluralidad de discursos, enmarcados entre la línea burguesa más moderada y la vertiente socialista, y su prioritaria preocupación inicial por la igualdad jurídica y la promoción de la educación. No obstante, aunque ambos movimientos no se caracterizaron por una temprana reivindicación del sufragio, las feministas mantuvieron destacadas implicaciones políticas como la militancia en los partidos republicanos y su compromiso en pro de la instauración de la república en sus respectivos países.

Sin embargo, pese a dicha entrega, la desconfianza de los políticos republicanos ante el destinatario del voto femenino, aunque con desenlaces diferentes, fue compartida por las repúblicas peninsulares. En Portugal, lejos de reconocer los esfuerzos de las mujeres en el advenimiento de la República, los políticos traicionaron sus iniciales promesas de reconocimiento de ciudadanía política a las mujeres, mientras que las españolas pudieron revertir tal pretensión, debido al arrojo y el tesón de una feminista que consiguió imponer en la Cámara el sentir de las sufragistas españolas, cuya movilización no era desdeñable en ese momento, y a una serie de intereses políticos de los grupos que apoyaron el voto femenino. Por otro lado, el tiempo jugó a favor de la causa española, al aprobarse la Constitución de 1931 en un contexto internacional favorable al sufragio universal. 
El miedo a la derechización de las repúblicas o directamente a su fracaso retrasó también el reconocimiento del voto a las francesas en 1919,1922, 1932, 1935. Aunque ese mismo temor llevó también a que algunas feministas, en ambos países ibéricos, defendieran un voto femenino restringido solo a unas determinadas mujeres. Fue el caso de Victoria Kent y, en un primer momento, de Carmen de Burgos en España, pero también de Ana de Castro Osório y Carolina Ângelo en Portugal. No obstante, a ambos lados de la frontera hispano-portuguesa destacaron mujeres excepcionales que demostraron no replegarse fácilmente ante los inconvenientes, como Beatriz Ângelo o Clara Campoamor, que defendieron apasionadamente su derecho y el de sus congéneres a votar.

En ambos países resultó menos difícil ver reconocidos la igualdad jurídica y determinados derechos sociales que los políticos. En ese sentido, las respectivas constituciones reconocieron derechos muy similares a las mujeres, aunque con veinte años de diferencia a favor de las portuguesas, salvo en el caso del sufragio. No obstante, esto no es óbice para que persista, como parece, en el imaginario colectivo portugués la idea de cierto retraso de su feminismo respecto al español. Lejos de ser así, según los episodios señalados, las más destacadas asociaciones de portuguesas, así como su internacionalización, se organizaron con anterioridad a las españolas.

Las feministas de ambos lados de "la raya", en muchos casos republicanas y masonas, compartieron reivindicaciones, experiencias y amistad, incentivando el ambiente cultural y creando redes que les permitieran trabajar conjuntamente en pro de sus derechos. Es el caso de Carmen de Burgos y Ana de Castro Osório, Maria Veleda y Belén Sárraga, o la propia Alice Pestana, que difundían sus respectivas actividades para visibilizarlas, organizaban congresos feministas y generaban ideas y modelos, impulsando un movimiento feminista peninsular.

Subrayamos, por tanto, los numerosos puntos en común entre los movimientos de mujeres españoles y portugueses, las semejanzas en los procesos de lucha y de conquista de sus derechos, los paralelismos entre las propias feministas y especialmente su compromiso con el advenimiento de la república en sus respectivos países como la coyuntura propicia para conseguir la igualdad. Dichos regímenes brindaron a las mujeres oportunidades inéditas y representaron las épocas de mayor reconocimiento de sus derechos, especialmente en las primeras etapas de los mismos. Sin embargo, en ambos persistió el temor masculino a que se cuestionaran los papeles tradicionales asignados a cada sexo y trataron de primarse los intereses políticos generales frente al reconocimiento de la plena igualdad entre los sexos. 


\section{Referencias bibliográficas y fuentes}

Aguado, Ana, e Luz Sanfeliu. 2021. "El camino de la liberación. Asociacionismo femenino y culturas obreras en la Segunda República (1931-1936)." Pasado y Memoria. Revista de Historia Contemporánea(22):237-263.DOI:https:/ / doi.org/10.14198/PASADO2021.22.08

Amorós, Celia. 2009. Vetas de Ilustración. Reflexiones sobre feminismo e islam. Madrid: Cátedra.

Ballesteros, Rosa $M^{a}$. 2002. "El despertar de un movimiento social: el feminismo en Portugal." In Discursos, realidades, utopías: la construcción del sujeto femenino en los siglos XIX y XX, coordinado por Dolores Ramos Palomo e Ma. Teresa Vera Balanza, 165-212. Barcelona: Anthropos.

Bock, Gisela. 2001. La mujer en la historia de Europa. Barcelona: Crítica.

Branciforte, Laura. 2015. "Experiencias plurales del feminismo español en el primer tercio del siglo pasado: un balance de la historiografía reciente." Revista de Historiografía 22: 235-254.

Campoamor, Clara. 1981. El voto femenino y yo. Mi pecado mortal [1 $1^{\text {a }}$ ed. 1935]. Barcelona: Saavedra.

Castro, Zília Osório de, João Esteves, e Natividade Monteiro (dirs.). 2011. Mulheres na I República. Percursos, conquistas e derrotas. Lisboa: Ediçoes Colibrí.

Castro, Zília Osório de. 2011. “As intelectuais". In Mulheres na I República. Percursos, Conquistas e derrotas, coordinado por Zilia Osório de Castro, João Esteves e Natividade Monteiro, 79-107. Lisboa: Ediçoes Colibrí.

Comesaña, Alfredo. 2014. “1919 Portugal en el laberinto.” Tesis Doctoral. Madrid: UNED.

Cortes españolas. 1931. "Debate sobre el voto femenino". Diario de Sesiones de las Cortes 1 de octubre de 1931 (48): 1349-1361. Disponible en <https://app.congreso.es/est_ sesiones / > [Consultado 4 de agosto de 2020].

Cortes españolas. 1931. "Debate sobre el voto femenino". Diario de Sesiones de las Cortes 1 de septiembre de 1931 (30): 693-703. Disponible en <https://app.congreso.es/est_ sesiones / > [Consultado 20 de julio de 2020].

Cortes españolas. 1931. "Debate sobre el voto femenino". Diario de Sesiones de las Cortes 2 de septiembre de 1931 (31): 728-729. Disponible en <https://app.congreso.es/est_ sesiones / > [Consultado 20 de julio de 2020].

Cortes españolas. 1931. "Debate sobre el voto femenino". Diario de Sesiones de las Cortes 30 de septiembre de 1931 (47): 1337-1342. Disponible en <https:/ / app.congreso.es/ est_ sesiones / > [Consultado 3 de agosto de 2020].

Cortes españolas. 1931. "Debate sobre el voto femenino". Diario de Sesiones de las Cortes 1 de diciembre de 1931 (83): 2736-2752. Disponible en <https:/ / app.congreso.es/est_ sesiones / > [Consultado 3 de agosto de 2020].

Cova, Anne. 2011. “O Conselho Nacional das Mulheres Portuguesas e as organizações internacionais de mulheres, 1914-1947." In Olhares sobre as Mulheres. Homenagem a Zilia Osório de Castro, coordinado por Irene Tomé, $\mathrm{M}^{\mathrm{a}}$. Emilia Stone e $\mathrm{M}^{\mathrm{a}}$. Teresa Santos, 27-40. Lisboa: Universidade Nova de Lisboa.

Cuesta, Josefina (dir.). 2003. Historia de las mujeres en España. Siglo XX. Madrid: Instituto de la Mujer.

De la Torre Gómez, Hipólito. 1997. "Historiografía española del Portugal contemporáneo." Ayer 26: 65-80.

De Luis Martín, Francisco. 2005. “El fracaso de la primera república portuguesa (1910-1926): razones de una crisis." Stvdia Historica. Historia Contemporánea 23: 221-248. 
Del Moral Vargas, Marta. 2010. “En los márgenes del poder, en primera línea de las manifestaciones obreras: la representación de la militancia femenina en el Partido Socialista (1906-1927)." Feminismo/s 16: 107-138. DOI: http://dx.doi.org/10.14198/fem. 2010.16.06

Espigado Tocino, Gloria. 2002. “Las mujeres en el anarquismo español (1869-1939)." Ayer 45: 39-72.

Esteves, João. 2008. Mulheres e republicanismo (1908-1928). Lisboa: Comissão para a Cidadania e Igualdade de Género.

Esteves, João. 2011a. “Contactos internacionais do Feminismo Português (1906-1928)." In Olhares sobre as Mulheres. Homenagem a Zilia Osório de Castro, coordinado por Irene Tomé, $\mathrm{M}^{\mathrm{a}}$. Emilia Stone e $\mathrm{M}^{\mathrm{a}}$. Teresa Santos, 163-175. Lisboa: Universidade Nova de Lisboa.

Esteves, João. 2011b. “Feminismo, feminismos e sufragismo na $1^{a}$ República." In Mulheres na I República. Percursos, conquistas e derrotas, coordinado por Zilia Osório de Castro, João Esteves e Natividade Monteiro, 19-46. Lisboa: Ediçoes Colibrí.

Fagoaga, Concepción. 1985. La voz y el voto de las mujeres. El sufragismo en España 1877-1931. Barcelona: Icaria.

Folguera, Pilar. 1994. “La II República. Entre lo público y lo privado, 1931-1939." In Historia de las Mujeres en España, coordinado por Pilar Folguera et al., 493-514. Madrid: Síntesis.

Gobierno de la República Española. 1931. Constitución. Disponible en <http:/ / www.congreso .es/docu / constituciones / 1931/1931_cd.pdf> [Consultado el 2 de agosto de 2020].

Gobierno de la República Portuguesa. 1910 Leis da Familia. Disponible en <http: / / bibliotecaparticular.casafernandopessoa.pt/3-61> [Consultado el 5 de agosto de 2020].

Gobierno de la República Portuguesa. 1910. "Lei do Divórcio". Diário do Govêrno, 4 de Noviembre. Disponible en <http://purl.pt/30055/4/sc-10740-3-p_PDF/sc-107403-p_PDF_24-C-R0150/sc-10740-3-p_0000_1-32_t24-C-R0150.pdf > [Consultado el 5 de agosto de 2020].

Gobierno de la República Portuguesa. 1911. Constitución. Disponible en <https: / www.parla mento.pt/Parlamento/Documents/CRP-1911.pdf> [Consultado el 5 de agosto de 2020].

Gómez-Ferrer Morant, Guadalupe. 2011. Historia de las mujeres en España: siglos XIX y XX. Madrid: Arco Libros.

Jiménez, Juan Carlos. 2000. “Portugal-España, 1890-1898. Una perspectiva comparada.” In Portugal y España en la crisis de entresiglos (1890-1918), coordinado por Hipólito de la Torre e Juan Carlos Jiménez, 25-40. Madrid: UNED.

Ledesma, José Luis. 2017. “Los años treinta y cuarenta desde abajo: La Historia Social y la Historiografía reciente sobre la Segunda República, la Guerra Civil y la primera posguerra." Stvdia Historica. Historia Contemporánea 35: 25-40.

López Villaverde, Ángel Luis. 2017. La Segunda República (1931-1936). Las claves para la primera democracia española del siglo XX. Madrid: Sílex.

Mariano, Fátima. 2011. As Mulheres e a I República. Casal de Cambra: Caleidoscópio.

Núñez Rey, Concepción. 2014. “Un puente entre España y Portugal: Carmen de Burgos y su amistad con Ana de Castro Osório." Arbor 190(766) a115: 7-12. DOI: https: / / doi.org/ 10.3989/arbor.2014.766n2007

Oliveira, César. 1985. Portugal e a II República de Espanha (1931-1936). Lisboa: Perspectivas \& Realidades.

Penche González, Jon. 2011. “Republicanismo en España y Portugal (1876-1890/91). Una perspectiva comparada." História: Revista da Faculdade de Letras da Universidade do Porto 1(1): 155-170. 
Pimentel, Irene Flunser, e Helena Pereira de Melo. 2015. Mulheres portuguesas. Lisboa: Clube do Autor.

Ramos Palomo, Ma Dolores. 1988. “Luces y sombras en torno a una polémica: la concesión del voto femenino en España (1931-1933)." Baetica 11: 563-573.

Ramos Palomo, $\mathrm{M}^{\mathrm{a}}$ Dolores. 2013. "Notas históricas e historiográficas sobre las mujeres en el republicanismo español." In Historia(s) de mujeres en homenaje a $M^{a}$ Teresa López Beltrán, coordinado por Pilar Pezzi Cristóbal, 317-333. Málaga: Asociación de Estudios Históricos sobre la Mujer.

Ramos Palomo, $\mathrm{M}^{\mathrm{a}}$ Dolores. 2014. "La construcción cultural de la feminidad en España: desde el fin del siglo XIX a los locos y politizados años veinte y treinta." In Feminidades y masculinidades: arquetipos y prácticas de género, coordinado por Mary Nash, 21-46. Madrid: Alianza.

Rollo, Maria Fernanda (coord.). 2013-14. Dicionário de História da I República e do Republicanismo. Lisboa: Assembleia da República.

Rosas, Fernando, e Maria Fernanda Rollo (coords.). 2010. História da Primeira República Portuguesa. Lisboa: Tinta da China.

Ruiz Franco, Rosario. 2006. “La República de las mujeres.” Espacio Tiempo y Forma 18: 171-185.

Samara, Maria Alice. 2007. Operárias e Burguesas: as mulheres no tempo da República. Lisboa: Esfera dos Livros.

Scanlon, Geraldin. 1986. La polémica feminista en la España contemporánea, 1868-1974. Madrid: Akal.

Tavares da Silva, Maria Regina. 2013. Carolina Beatriz Ângelo (1878-1911). Lisboa: Comissão para a Cidadania e a Igualdade de Género.

Tengarrinha, José. 1997. “La historiografía portuguesa en los últimos 20 años.” Ayer 26: 19-64.

María de la Paz Pando Ballesteros. Profesora de Historia Contemporánea, periodo sobre el que imparte docencia. Miembro del Centro de Estudios de la Mujer y Directora del Seminario Internacional de Historia Contemporánea de los Derechos Humanos de la Universidad de Salamanca. El análisis de la Democracia Cristiana española desde la dictadura franquista a la democracia a través de la Revista Cuadernos para el Diálogo, así como la Historia de los Derechos Humanos, incluidos los de las mujeres, representan sus líneas de investigación.

Correo electrónico: mpaz@usal.es

Artículo recibido el 03 de Octubre de 2020 y aceptado para su publicación el 31 de Marzo de 2021. 
